\title{
Developments in stiff ground support in deep potash operations at the Vanscoy Mine
}

\author{
TJ Coleman SRK Consulting (Canada) Inc., Canada \\ DD Neely Nutrien, Canada
}

\begin{abstract}
This paper presents a case study of the development of ground support practices at Nutrien's Vanscoy potash mine, the deepest $(>1,100 \mathrm{~m})$ conventional evaporite mine in North America.

The majority of the underground excavations at Saskatchewan potash mines are unsupported and rely upon the principle of stress control to manage ground conditions. Adverse ground conditions are typically addressed in three ways: changing mining horizon to avoid disturbed ground, cutting down of bad ground, or installation of ground support. The two former approaches often result in extended interruptions to production whereas installation of ground support allows access to be maintained and production to continue.

The time-dependant creep properties of the evaporites led to the historical approach of using a soft ground support system to accommodate the large deformations typically seen. The softness of the ground support system at potash operations was typically achieved by utilising point anchored mechanical rockbolts, partial encapsulation of resin rebar bolts, or by introducing a softer element in to a fully encapsulated resin rebar support element, at Vanscoy a wood washer was used.

The experience of one of the authors with the improvement of excavation stability following the introduction of stiff resin encapsulated AT rockbolts for secondary ground support at the deep $(>1,300 \mathrm{~m})$ Boulby potash mine in the UK led to initial instrumented trials at the Vanscoy Mine.

Multipoint magnesonic extensometers were introduced to the mine to provide detailed measurement of back deformation to assess the impact of increasing the ground support stiffness on back behaviour. The magnesonic extensometers comprise of 20 magnetic reference anchors installed over a depth of $7 \mathrm{~m}$ allowing precise high resolution measurement of back deformation. The introduction of magnesonic extensometers to monitor the influence of stiffening the ground support system proved invaluable in understanding the mechanism of ground support/rock mass interaction in the immediate stratified back of development and production excavations.
\end{abstract}

The Vanscoy Mine has adopted stiffer ground support practices and continues to explore other ground support technologies in the pursuit of safe optimised ground support practices.

Keywords: potash, ground support, Vanscoy Mine, evaporite mine

\section{Introduction}

The Vanscoy Mine is located approximately $32 \mathrm{~km}$ southwest of Saskatoon, Saskatchewan, Figure 1. The mine has been in production since January 1969 and excavates sylvinite potash ore from the Patience Lake Member of the Prairie evaporites. The Vanscoy Mine is the deepest conventional potash mine in North America and as such has ground conditions that are considered to be unique amongst the potash mines in the Williston Basin. 


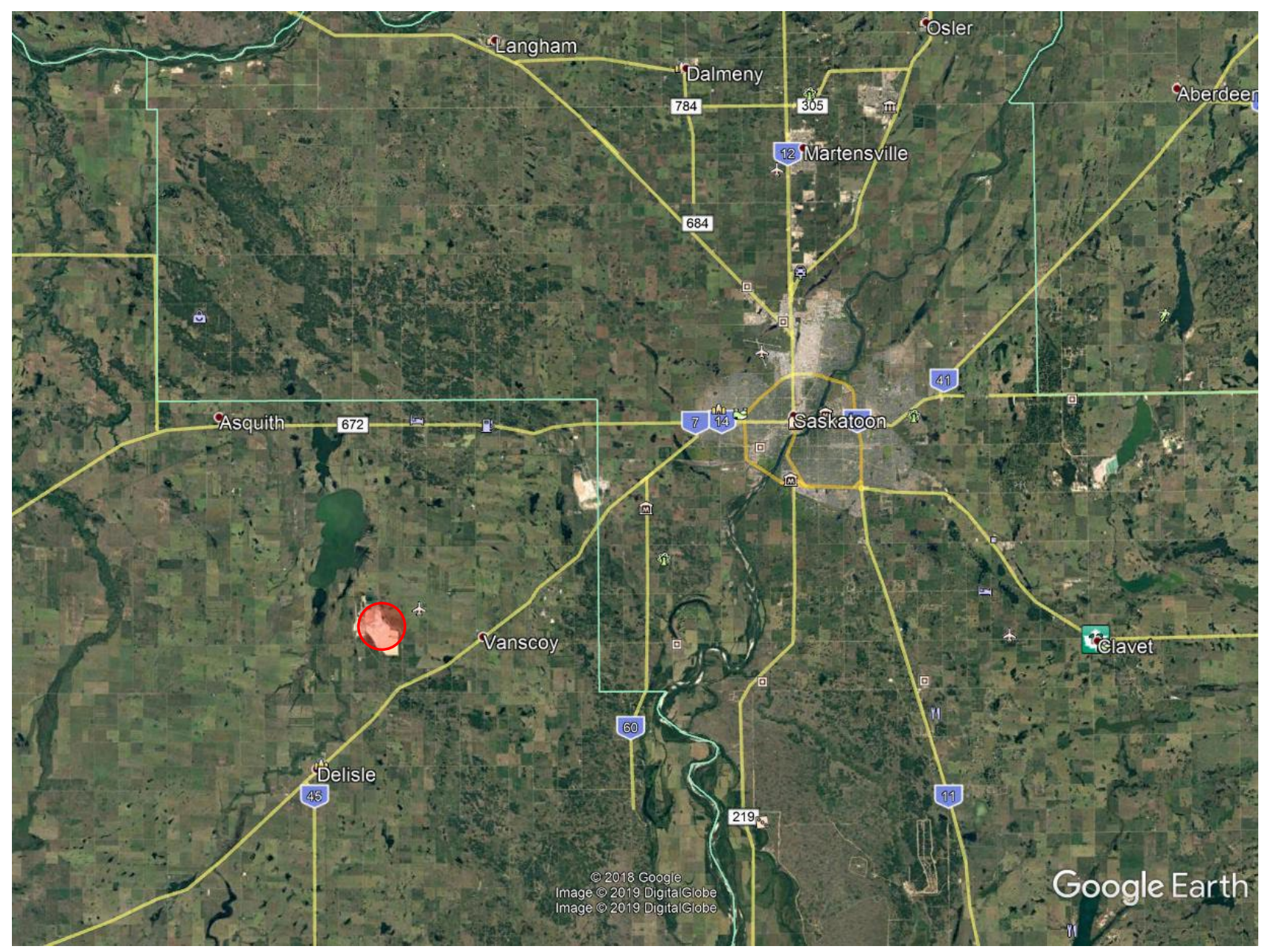

Figure 1 Location of the Vanscoy Mine shafts shaded in red. Approximately $32 \mathrm{~km}$ southwest of Saskatoon

The mine extends approximately $23 \mathrm{~km}$ from north to south and $18 \mathrm{~km}$ from east to west with the majority of the mining occurring in the northern half of the lease, Figure 2. The two shafts are located approximately midway between the northern and southern lease boundaries. Historically, the depth of mining in the northern part of the mine has been between 1,033 and 1,077 $\mathrm{m}$. The current and future mining area south of the shafts will take the ultimate depth of operations to $1,115 \mathrm{~m}$.

The majority of extraction of potash ore has been mined using Marietta twin rotor borer miners with an extensible conveyor. These machines cut a room $5.5 \mathrm{~m}$ wide by $3.35 \mathrm{~m}$ high; rooms are widened out to $10.5 \mathrm{~m}$ by taking a second pass. The borer miners typically mine rooms approximately $1.6 \mathrm{~km}$ in length. When a second pass is to be taken, a turnaround area is mined at the end of a room and then the miner cuts the second pass on retreat. These long rooms are grouped into panels comprising five rooms which are then separated by a barrier pillar. Recent changes have been made to the production panel geometry with the introduction of a chevron pattern that provides more flexibility for the management of ground conditions in the deeper part of the mine.

Heliminer type continuous miners with shuttle cars are used for rehabilitation of unstable excavations and where borer miners are unable to operate efficiently. 


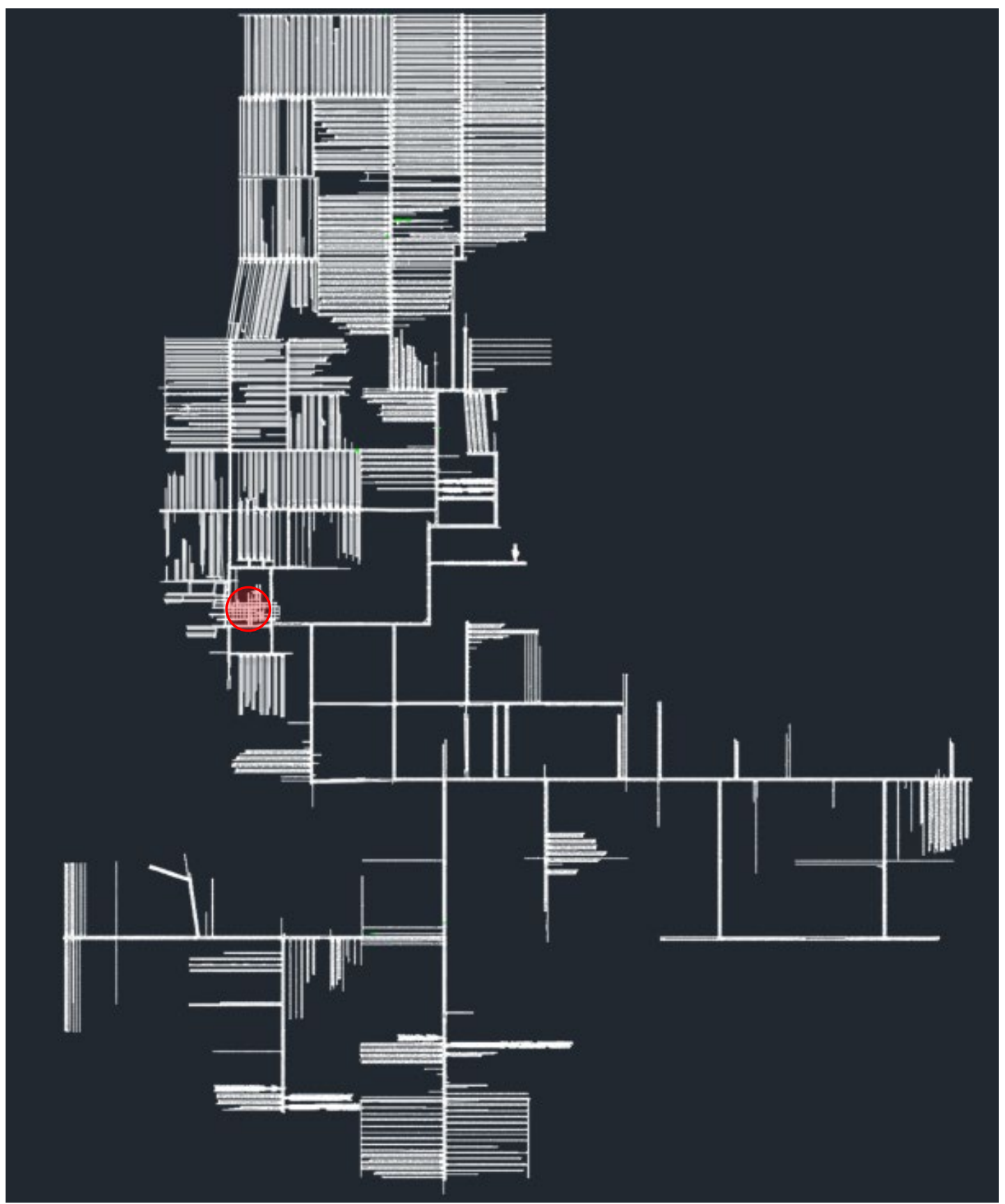

Figure 2 Vanscoy Mine plan; shaft pillar area highlighted in red

\section{Geology}

The potash of the Prairie Evaporite is located within a $150 \mathrm{~km}$ wide, $600 \mathrm{~km}$ long band that stretches across south central Saskatchewan from the Manitoba border west to Alberta. The lower part of the evaporite sequence comprises mostly halite and anhydrite with some dolomite. The potash horizons are found in the upper $60 \mathrm{~m}$ of the formation. Of the three potash horizons in the Prairie Evaporite, the Vanscoy Mine exploits the uppermost horizon, the Patience Lake Member.

The Patience Lake Member is overlain by salt cover with an average thickness of $14 \mathrm{~m}$, above this is an argillaceous shale unit, the second Red Beds, approximately $4 \mathrm{~m}$ thick. The Dawson Bay limestone, which in some areas is water bearing, overlies the second Red Beds.

Underlying the Prairie Evaporite is the Winnipegosis Formation, a carbonate formation with pinnacle reefs that attained heights of up to $70 \mathrm{~m}$. These localised pinnacle reefs lead to variations in the topography of the 
evaporite horizon. The pinnacle reefs in the Winnipegosis are sometimes associated with solution collapse features formed as a result of post-depositional evaporite leaching and collapse of the overlying sedimentary rocks. The chimney like solution collapse features are a significant hazard to underground mining as they provide a direct link between the overlying water bearing horizons and the mining horizon. Localised geologic disturbance of the ore horizon and adjacent beds occurs as a result of syn- and post-depositional leaching and reworking. Mine procedures require modification of the standard mining practices and the installation of ground support to manage the associated ground control risk with these disturbances and leached zones.

The $14 \mathrm{~m}$ thick salt cover comprises several beds of halite interbedded with minor shale and clay bands and a sylvinite layer free of clay bands. The typical stratigraphy of the mining horizon is shown in Figure 3.

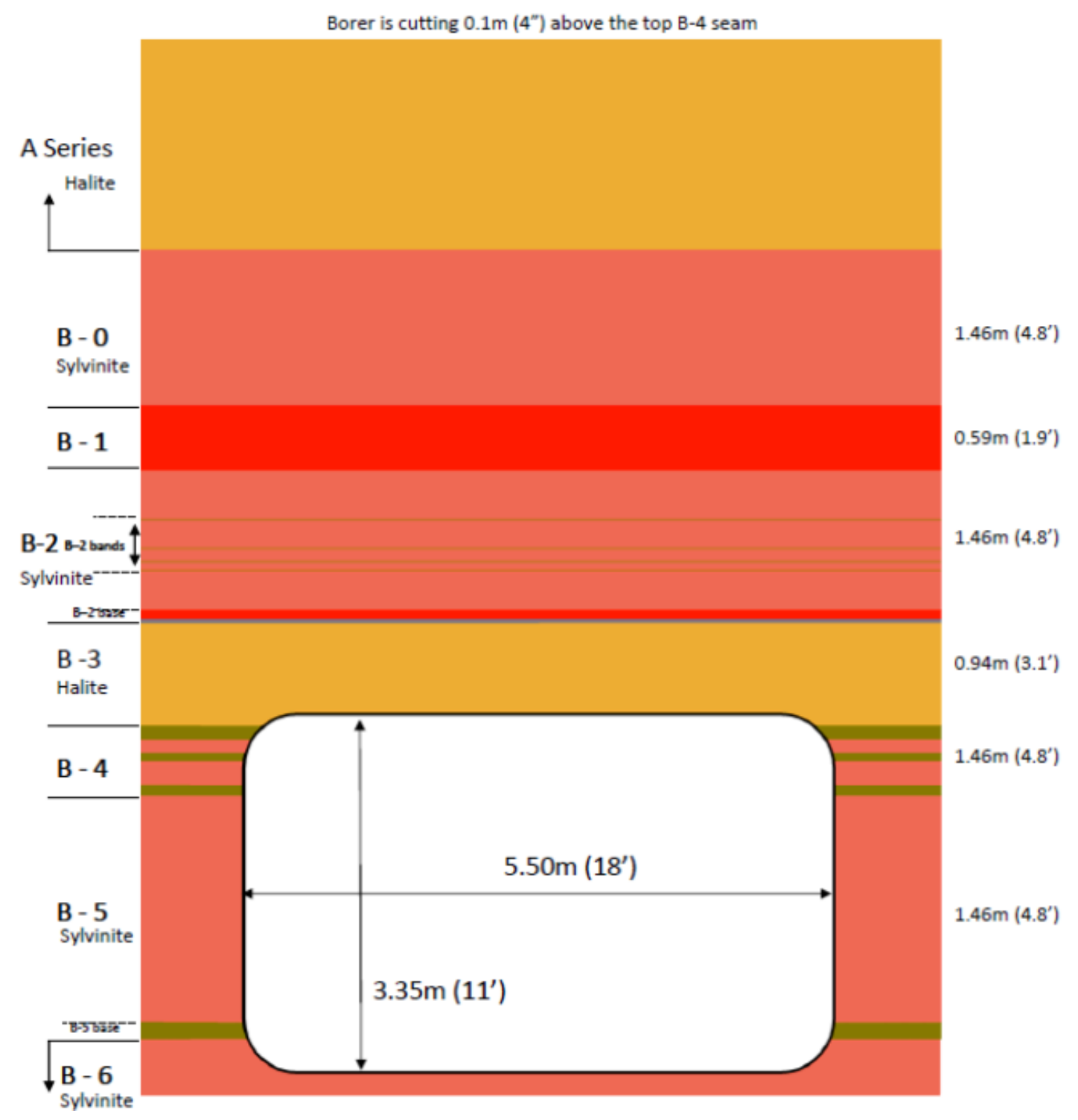

Figure 3 Typical geologic section at the mining horizon

The B4 clay seams must be removed during mining to prevent unstable roof conditions. A clay band is also present just above the floor of the mining cut at the base of the B5 seam. The B4 and B5 clay seams are critical to the rock mechanics performance of pillars as they allow lateral dilation of pillars to occur while reducing the transfer of lateral load onto the roof and floor rocks. The early challenges associated with mining at the Vanscoy Mine and the importance of the clay bands to the performance of the mining rooms was identified after various approaches were tried to achieve safe efficient extraction of the potash ore. A summary of the approaches and the rock mechanics aspects of them is summarised in Mackintosh (1975), Figure 4 illustrates the impact of the clay bands on both pillar and back performance. Additional clay/shale 
bands are located above the mining cut at the B3/B2 boundary and the B2-bands. Dilation and separation of the back localises on and around these bands.

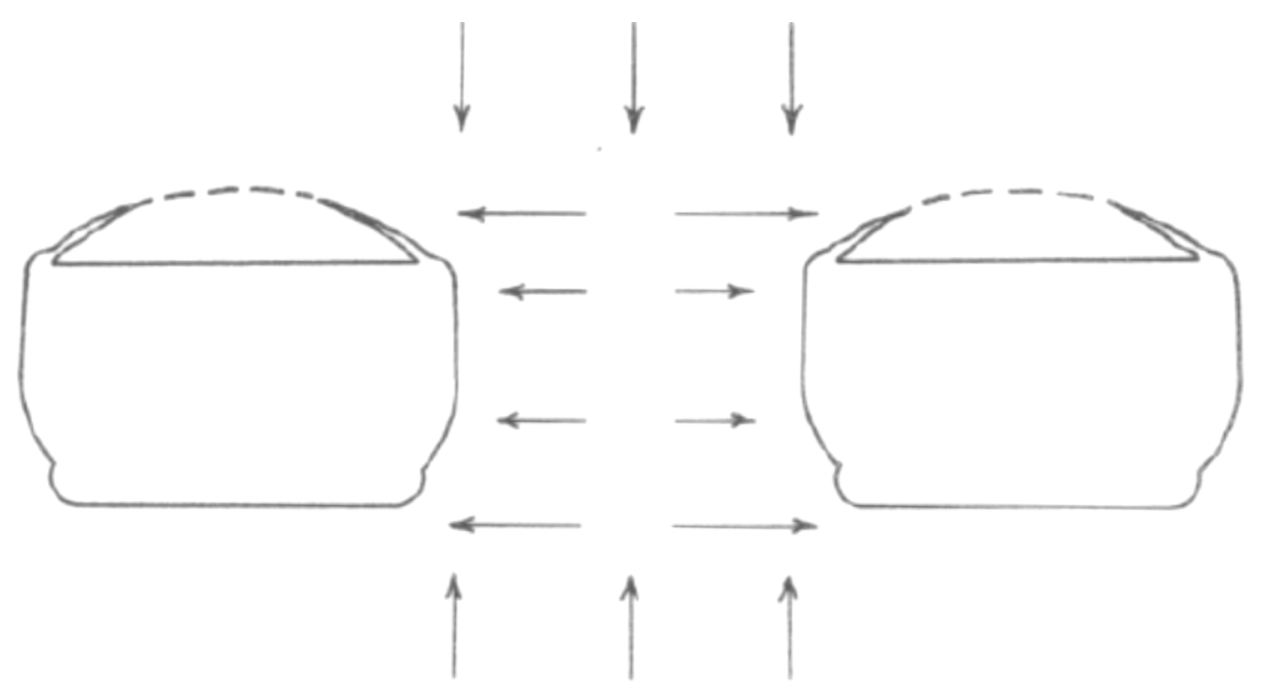

Without friction reducing effect of clay bands, expansion of the pillar results in development of lateral loads in the back and associated shear formation.

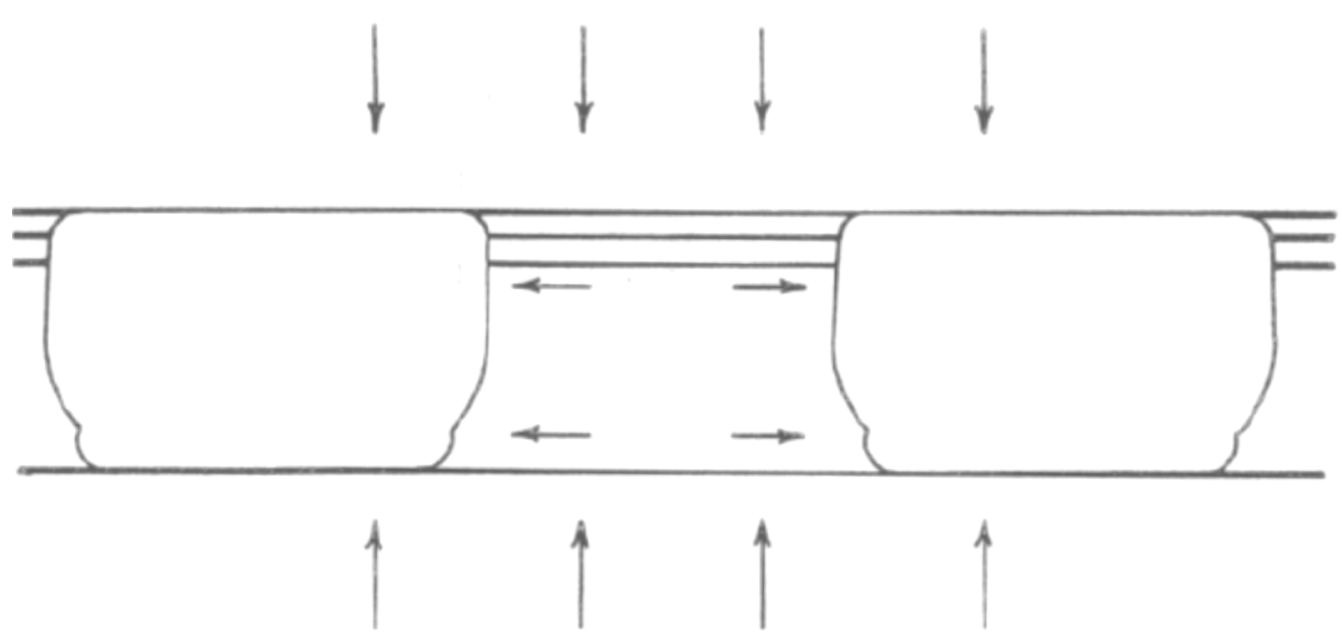

Friction reducing effect of clay seams protects the back from induced loads associated with pillar expansion.

Figure 4 Clay band influence on pillar and back performance (Mackintosh 1975; Figure 7a and 7b)

\section{$3 \quad$ History}

Mining at the Vanscoy Mine has been conducted successfully using the same mining geometry for nearly 40 years. As mine operations have become more extensive with a growth of the mine in to the southern part of the mining lease and recovery of remnant areas in the north of the mine ground control issues appear to have become more frequent. 
The initial mine plan for exploitation of the potash resource at Vanscoy was, like all of the other mines started during the Saskatchewan potash boom between 1960 and 1970, conventional room and pillar mining. These layouts were based very much upon the mining geometry of relatively shallow salt mining operations.

Comprehensive rock mechanics programmes were initiated at many of the mines in order to address the ground control issues. Attempts at applying rock mechanics theory from hard rock mines, i.e. narrowing room spans to address back stability issues, often resulted in deterioration of ground conditions and not an improvement.

This technique resulted in significant back stability issues and low productivity; all but one of the Saskatchewan mines constructed during this period moved away from this geometry to variations of the long room and pillar geometry that is based upon the stress relief/control technique originally proposed by Serata (1972).

When a new mining block is developed the main entries are mined using a modified version of the stress relief technique proposed by Serata (1972). This technique was first developed at the Vanscoy Mine in 1969 when conventional room and pillar techniques resulted in significant back stability issues and low productivity (Prugger, 1979). The initial design consisted of three rooms, two outer relief drifts and a central protected drift, resulting in an immediate improvement in ground conditions. Continued experimentation and refinement of the geometry ultimately led to the five entry system that is used for the main entries today.

Production mining uses another variation of the long room and pillar stress relief/control technique. The long room and pillar method was pioneered to suit the productivity advances that were made available with extensible conveyors and the high advance rates achievable with multi-rotor borer miners. Two variations of the long room and pillar mining method are now in use: one comprises constant the key difference being the room width and pillar size.

Variations on the long room and pillar technique have centred on room spans, pillar widths and the grouping of rooms. Current mines using this technique typically have a maximum room span of $20 \mathrm{~m}$ and a variable pillar size to result in a maximum extraction ratio of $40 \%$ to $50 \%$. The long room and pillar method utilised at Vanscoy uses closely spaced rooms of 5.5 to $10.5 \mathrm{~m}$ span with small yield pillars of 5.5 to $6.7 \mathrm{~m}$ pillars.

Until recently production mining was dominated by the five room mining geometry that has changed little from the designs developed in the mid-1970s. These designs were based on the collection of detailed convergence and stress/pressure data and the observation of room behaviour. Convergence measurements were taken in the rooms and pressure cells were grouted into yield pillars to determine the relationship between room closure, pillar deformation and the stresses within the pillar.

A variation of stress relief mining utilising chevron patterns has been adopted at the Vanscoy Mine in recent years. This technique relies on the same general stress control technique developed but advances entire panels at once rather than singular rooms. This technique limits time spent in ground which will relieve and therefore improves safety and reliability when in challenging ground conditions.

As with other Saskatchewan potash mines stable back conditions are achieved through the application of the stress control mining technique with very little use of rockbolting. Rockbolting has traditionally been required when 'drummy back' has been identified by sounding with a scaling bar or when separation on a mud or clay band has been measured by drilling a test hole in the back or from extensometer readings.

\section{$4 \quad$ Rock mechanics}

The design and assessment of underground excavations in evaporites has not benefited from the development of widely accepted empirical and numerical criteria that are available to the coal and metalliferous mining industries. During the early days of potash mining in Saskatchewan where ownership was widely distributed, each of the newly established mines developed their own approaches to determining the optimum mining geometry. There was some common ground in the acceptance of the time-dependant 
performance of excavations in evaporites and many attempts at establishing a common approach to excavation and pillar design, i.e. Serata's (1972) stress relief theory and the variations proposed by Mraz (1972, 1973), and Baar (1971), but with little success due to the secretive and competitive nature of the operators at the time. It was only with the amalgamation of many of the Saskatchewan potash mines under the Potashcorp banner and through the efforts of the non-Potashcorp mines to share information through the Saskatchewan Potash Producers Association (SPPA) and the Rock Mechanics Committee of the Saskatchewan Mining Association (SMA) that some sharing of knowledge became established.

Various studies of rock mechanics aspects of potash excavation design were conducted through the SPPA, SMA and CanMET (Canadian Centre for Mineral and Energy Technology) from the mid-1980s through to the mid-1990s. It is understood that little significant collaborative research in to potash rock mechanics has been conducted since the conclusion of these projects. Despite these significant efforts a common accepted method for determining excavation and pillar design has not been established and many differing approaches are used.

Two fundamental tools are available for the design and assessment of excavations, these are empirical and numerical models. In both cases the models are an appropriate simplification of reality. The challenge in both approaches is to identify the appropriate level of simplification, identify those aspects that are critical to the design, and the application of sound engineering judgement when interpreting the results.

Currently at the Vanscoy Mine the rock mechanics program centres around maintaining hundreds of instrumentation stations spread across the mine workings. Instrumentation is used to monitor typical areas as well as locations where ground control challenges are present. Observations document findings in the field surrounding areas where instrumentation is located to provide context for the instrument data collected. The program allows for a proactive approach to mining-induced stress related issues, data informed operational decisions including design changes and provides data which can be input into numerical models for calibration and verification.

Ground control management on the conventional Saskatchewan potash mines has historically relied upon the stress control method to prevent the development of adverse ground conditions and this has been largely successful. However adverse ground conditions are often associated with geological anomalies and changes in the mineralogical composition of the orebody and adjacent ground. These adverse ground conditions are typically addressed in three ways: changing mining horizon to avoid disturbed ground, cutting down of bad ground, or installation of ground support. The two former approaches often result in extended interruptions to production whereas installation of ground support allows access to be maintained and production to continue.

\section{$5 \quad$ Ground support}

The purpose of rockbolting is to provide support or reinforcement to the rock around an excavation to enhance the stability and thus safety of an excavation. The most effective way of achieving this is to design a rockbolting system in such a way that the rock is reinforced and can support itself. Current ground control philosophy is that the reinforcing elements should be 'bonded' to the rock mass along their full length so that the support provided is not strongly dependent on the rockbolt head, washer plate, and mechanical anchor at the end of the support element.

The stiffness of the reinforcement system is also of importance when choosing a reinforcement method for a particular set of ground conditions. Stiff support systems provide higher levels of support at lower levels of displacement than soft systems. Displacement and dilation of the rock around an excavation is associated with progressive failure of the rock. If an installed support system is stiff enough to minimise the displacements then it is possible to prevent or minimise the extent of failure. A point anchored, or partially encapsulated, rockbolting system generally does not have the required stiffness to achieve this. As the unbonded length of bolt deforms it allows deformation of the rock to take place, the amount of deformation is directly proportional to the unbonded length of the rockbolt. Typically, a stiff support system has a higher 
load capacity than a soft support system, so there is often a trade-off required between stiffness, capacity and permissible ground deformation.

In potash, the failure mechanism of resin anchored rebar support has been studied by Neely (2014). In general, a large dataset of pull tests of resin anchored rebar in potash was used to develop an equation which would approximate load required to develop separations of a given size along a bonded length. Within the elastic limit of the support, and with adequate bond length in place, the work demonstrated that rebar rockbolts allow minimal deformation of the ground along their bonded length within the elastic limits. This work concluded that given the stiffness of resin anchored rebar in potash, deformations measured in the field in areas where this support was used primarily indicate:

- The presence of an unbonded length (length of component which softens the response) allowing deformation.

- Insufficient bond length present on either side of a location where separation is occurring.

- Movement measured is present at the top of, or above rebar depth into back.

- The rebar support is beyond the yield load at this location.

The timing of support installation within the mining cycle can be critical in optimising the effectiveness of the ground support system. If installed too soon then the load on the rockbolts can be high and lead to early failure, if installed too late then ground deformations, particularly in lower strength bedded strata, can result in reduced effectiveness of the ground control system. If significant delamination of the back occurs prior to rockbolt installation, then resin can be lost into the voids resulting in poor resin mixing and reduced encapsulation length. When installing rockbolts in roadways and crosscuts that have been mined and left unsupported for a period of time it is important that the rockbolt installation crews record any voids that are detected by rapid feed or jumping of the drill steel. This information can be used to help determine the degree of dilation occurring in the back prior to ground support installation.

The standard ground support used at the Vanscoy Mine is a \#8 forged head rebar rockbolt ranging in length from 1.8 to $3 \mathrm{~m}$ long in a $28.6 \mathrm{~mm}$ diameter hole with a full column bond using Ground Lok H2O polyester resin with a wood washer plate sandwiched between the back and the standard steel washer plate. The wood washer was a nominally $40 \mathrm{~mm}$ thick softwood plate used to provide an indication of load on the bolt. Experience from the mine indicated that the wood washer was fully compressed as the load in the bolt approached the ultimate strength of the steel rebar.

The presence of the wood washer resulted in a localised softening of the ground system in the immediate back. Softening of the bolt is increased further with a debonded length near to the bolt collar from less than full column encapsulation. In order to mobilise the full strength of the bolt sufficient displacement is required to accommodate the thickness of the wood washer and the unbonded section of rebar.

The localised softening of the ground support system was not providing sufficient resistance to minimise the dilation of the back on the clay band found at the base of the B2 sylvinite horizon. Typical dilation on the base of $\mathrm{B} 2$ bands can clearly be seen in Figure 5. 


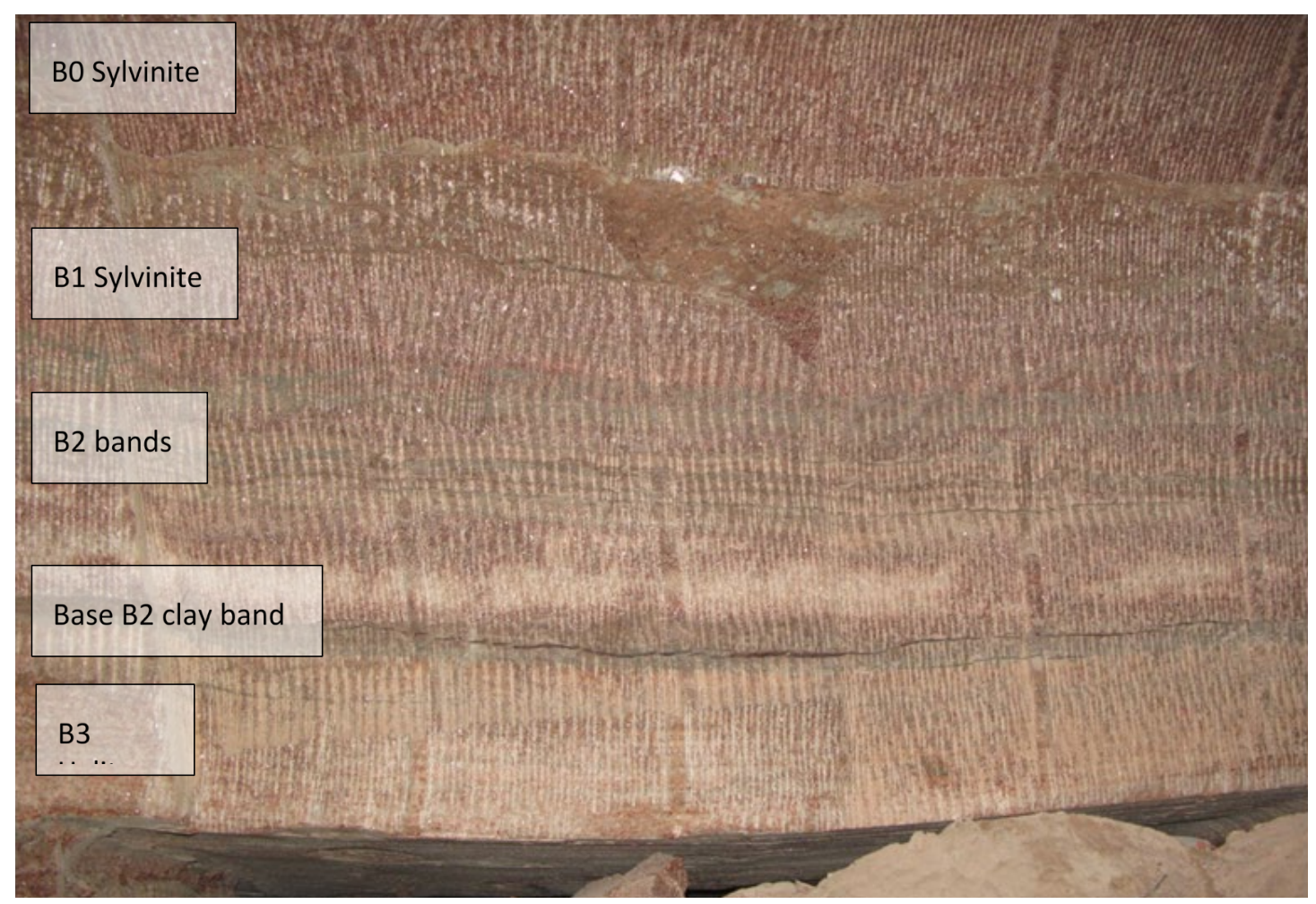

Figure 5 Clearly visible dilation of the back localised on the clay band at the base of the B2 sylvinite

Similar ground control challenges were faced at the Boulby Mine in the UK, the world's deepest conventional potash mine at over $1,300 \mathrm{~m}$ below surface. In this instance very high creep deformation rates required substantial secondary bolting to safely secure the back of both production and development excavations. This led to a search for alternate ground support strategies and ground support practices used in deep UK coal operations at the time were chosen for trials. The stiffer AT style bolts from the coal industry resulted in a substantial improvement in ground conditions which has led to their adoption for secondary ground support where challenging ground conditions were encountered. The authors' experience with this program in his role as Rock Mechanics Engineer at Boulby, and comparing the ground conditions observed at the Vanscoy Mine during regular ground control inspections, led to the suggestion of stiffening the ground support by removing the wood washer.

The first of several instrumented stiff ground support trials were initiated in late 2013 by the mine geology and rock mechanics team.

\section{$6 \quad$ Monitoring and instrumentation}

The adequacy of a ground support system needs to be continually monitored to ensure the system is appropriate for any changes in ground conditions. Field testing and analysis of the rock/support interaction, and periodic testing of ground support performance is essential to this process and especially when changes are considered to any component of the system.

\subsection{Magnesonic extensometers}

The extensometers in most common use at potash operations in Saskatchewan are simple single or dual height extensometers. Although these provide useful information of total back expansion they are unable to measure differential rates of displacement throughout bedded strata as is found in the back of the economic mining horizons of the Prairie Evaporite. The displacement measured by these instruments could be occurring over their full height e.g. $25 \mathrm{~mm}$ over $3 \mathrm{~m}$, or at a single bedding feature in the back, e.g. $25 \mathrm{~mm}$ separation on a single mud band. Although the reading from the instrument is the same, the implications for 
the stability of the excavation are potentially very different. Measurement from multiple elevations in the back is much better but installation of conventional multipoint borehole extensometers is challenging where more than two or three reference anchors are required.

An alternative method of recording the displacement at several locations within a borehole is the magnesonic extensometer. This technique was commonly used in underground coal mines and allows highly detailed measurement of ground movement. It is a highly accurate device $( \pm 0.2 \mathrm{~mm})$ that can measure the location of up to 20 anchor positions in a $7.5 \mathrm{~m}$ longhole.

The instrument consists of a flexible probe with a transducer head attached and a portable battery powered readout unit (see Figure 6). The probe is inserted into a predrilled hole, usually of $43 \mathrm{~mm}$ diameter, containing up to 20 permanent magnets which are anchored to the strata using a friction fit injection moulded plastic 'shuttlecock' device (see Figure 7).

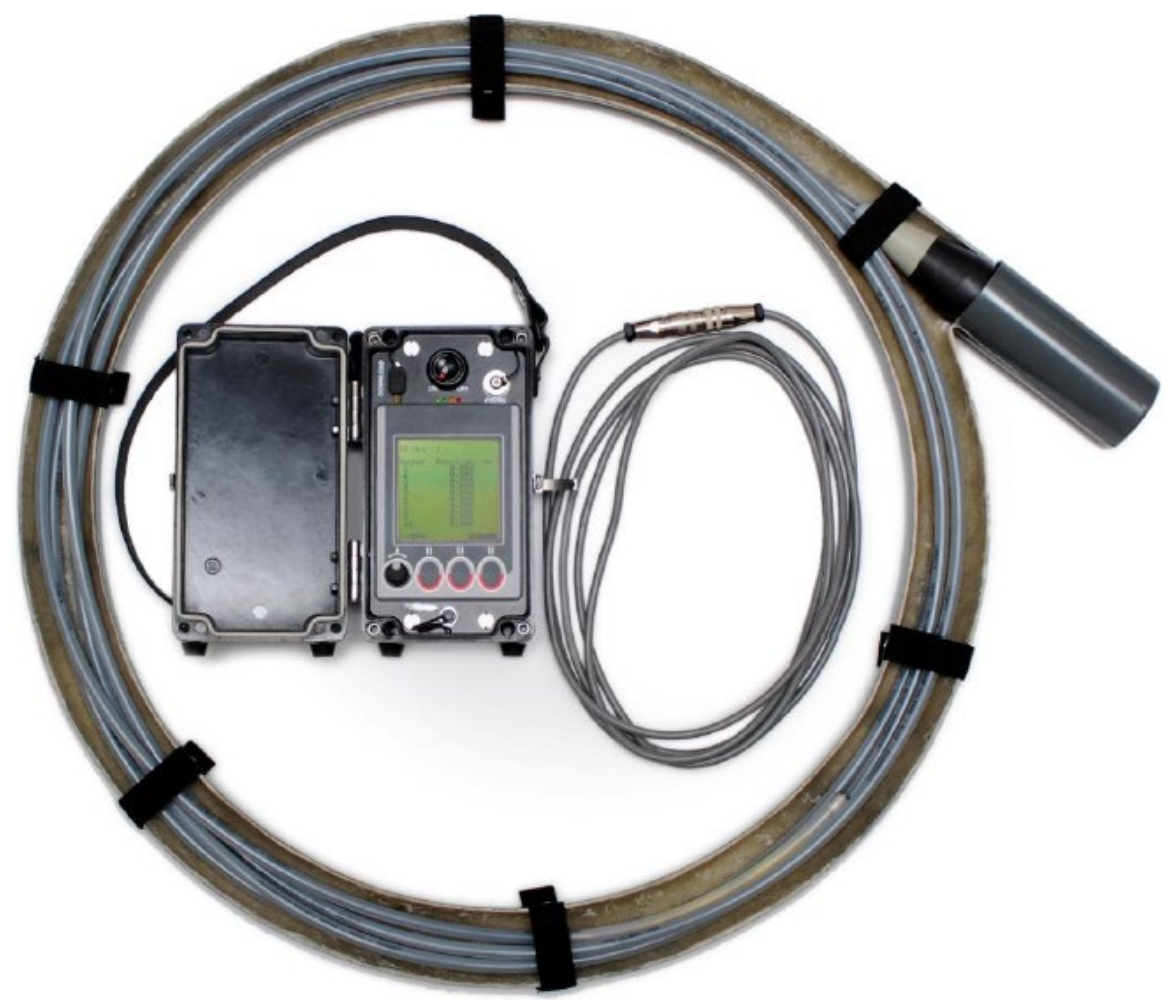

Figure $6 \quad$ Magnesonic probe and readout

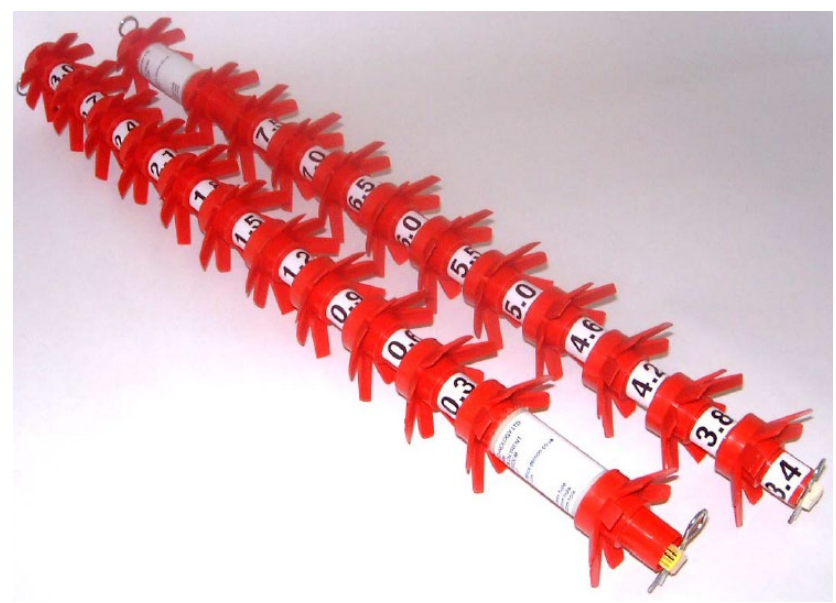

Figure 7 Magnesonic anchor set for $43 \mathrm{~mm}$ diameter drillhole on retainer. Each individual 'shuttlecock' is installed at the depth specified on the 'shuttlecock' 
The system has the advantage that probe and readout are only required when measurements are taken, the magnetic anchors to which the displacement is measured are robust, 'miner proof', and simple to install. As the sensitive measurement component is not permanently installed a single system can be used to measure strata movement at multiple locations, the probe is only inserted into the hole when a reading is to be taken.

When connected to the readout unit, the probe receives a small current pulse which travels along a thin walled metal tube within the probe. At each magnet position the interaction of the static field (due to the magnet) and the field (due to the current pulse) produces a torsional deformation in the thin walled tube. This deformation is transmitted down the tube as a 'sonic' pulse and detected by a torsional transducer located at the end of the probe. Sonic pulses from each magnet position arrive at the transducer head at different times, depending on how far they have travelled. The speed of the mechanically transmitted, sonic, pulse is known and, using a very accurate timer, the readout unit calculates and displays the positions of the magnets with high resolution.

The ability to record the displacement at many positions allows a detailed profile of strata displacement and dilation throughout the length of a $7.5 \mathrm{~m}$ hole; this ability makes it possible to identify the horizons where dilation occurs, determine the height of failure or roof softening, and to demonstrate the trend of strata deformation.

\subsection{Monitoring results}

The initial instrumented trials at Vanscoy comprised 20 magnesonic extensometers installed at several locations in the southern half of the mine. At each of the locations the back was either unsupported; supported with $2.4 \mathrm{~m}$ long \#8 full column resin grouted rebar with a wood washer plate; or, supported with $2.4 \mathrm{~m}$ long \#8 full column resin grouted rebar and no wood washer.

The magnesonic extensometers were read at typical intervals of between 7 and 14 days for a period of 18 months to over two years. Displacement data collected from a location in which the ground support had used a wood washer is shown in Figure 8. Data from a trial location that did not use a wood washer is presented in Figure 9. 


\section{Extensometer \#19 Displacement vs. Position}
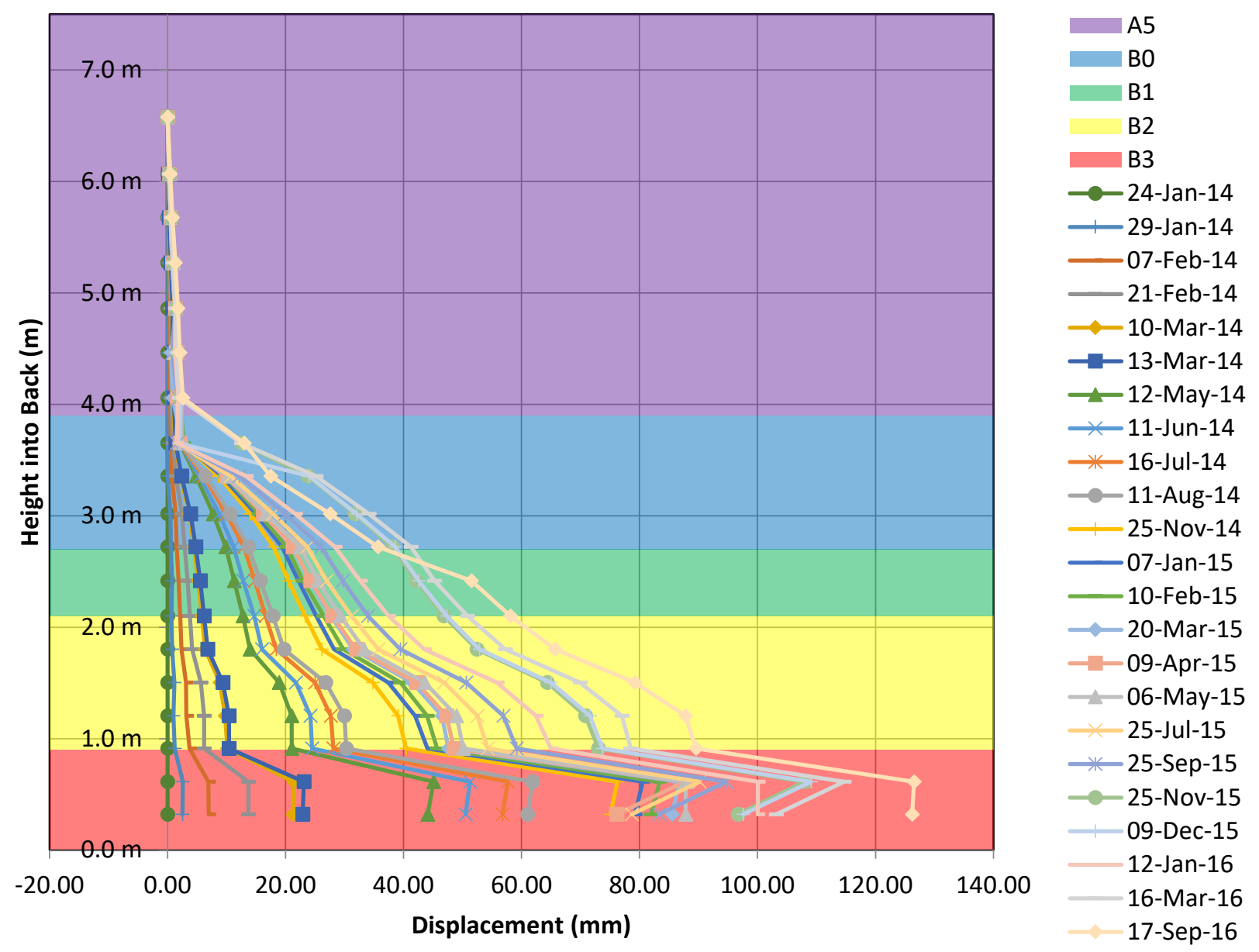

Figure 8 Extensometer displacement data collected from an excavation supported with rockbolts using a wood washer. The coloured bands represent the approximate location of the main stratigraphic layers present in the back of the excavation

The displacement plot in Figure 8 shows a clear kink in the curves at the base of the B2 sylvinite unit (yellow) that is detectable after less than two weeks following instrument installation. As time progresses the subsequent readings show the differential displacement at the base of the B2 becoming more pronounced with a difference of almost $30 \mathrm{~mm}$ after approximately 11 months. The $30 \mathrm{~mm}$ difference is roughly that of the wood washer once it has fully compressed between the steel bolt plate and the back of the excavation. Interestingly the general shape of the displacement curves above the B3 horizon suggest that the remaining bonded length of the rockbolt is also exhibiting soft behaviour as the $2.4 \mathrm{~m}$ long bolted height is not clearly visible.

The inclusion of the wood washer appears to have had a considerable influence on the behaviour of the whole bolt and not just the impact on the dilation of shallow bedding features. 


\section{Extensometer \#2 Displacement vs. Position}
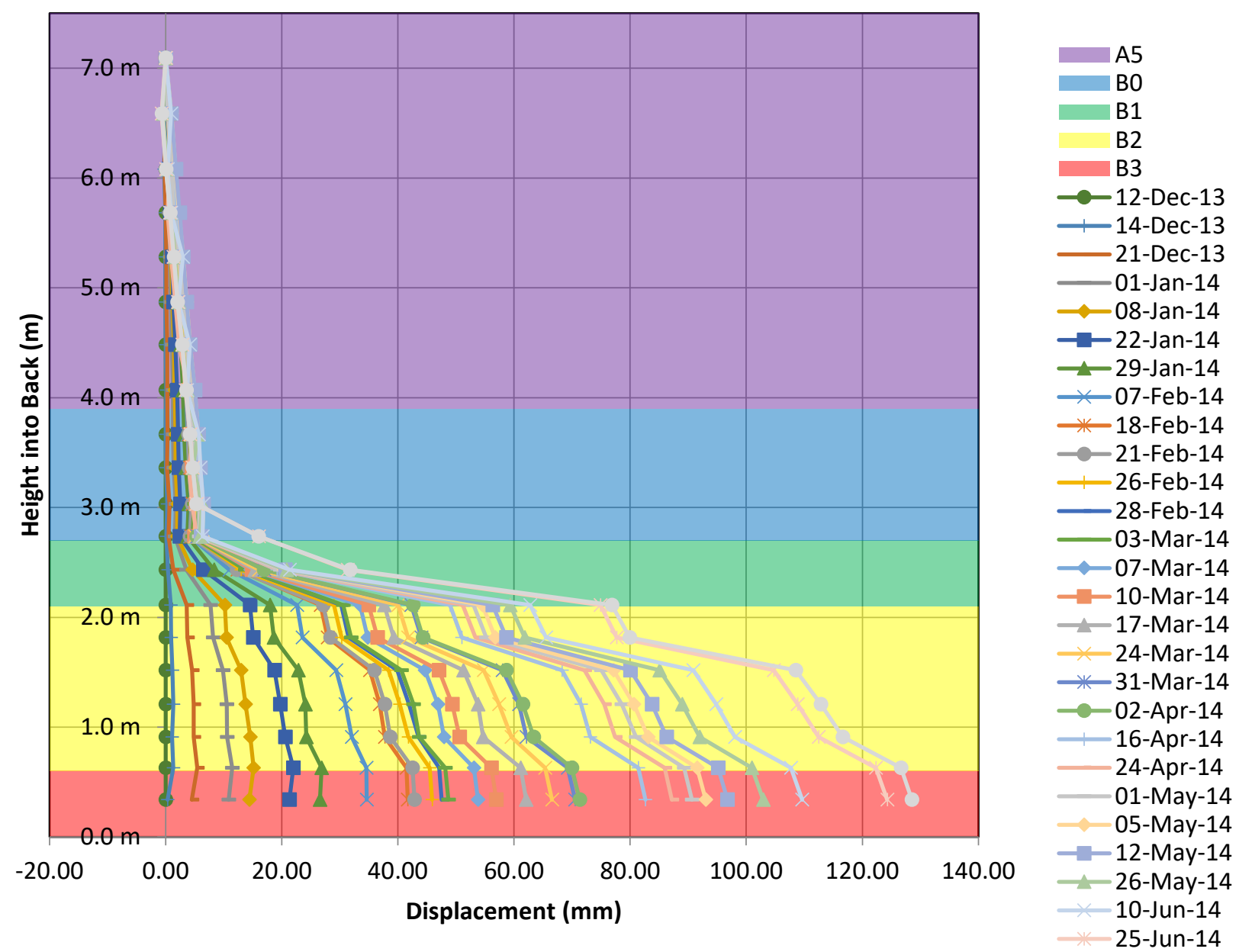

Figure 9 Extensometer displacement data collected from an excavation supported with rockbolts without a wood washer. The coloured bands represent the approximate location of the main stratigraphic layers present in the back of the excavation

The displacement plot in Figure 9 is from a location that had been bolted using full column resin grouted \#8 rebar without a wood washer plate. The shape of the displacement curves contrasts dramatically with that presented in Figure 8. The kink at the base of the B2 unit does not become clearly visible for some months and after nearly 18 months the differential displacement is in the order of $10 \mathrm{~mm}$. Larger displacements are observed at the approximate location of the B2 bands located approximately three quarters of the way up the B2 (yellow) horizon. The top of the bolted height of approximately $2.4 \mathrm{~m}$ is also clearly visible in the curves. The majority of deformation measured in is found above the rebar demonstrating that the ground behaving as a single competent beam with a thickness approximately equal to the length of rebar.

The total deformation in both bolting cases is similar, however the stiffer bolting system washer appears to have pushed the plastic deformation of the back above the bolted height. The stiffer ground support appears to have influenced the time-dependant creep behaviour of the sylvinite in the back with similar overall displacement magnitude but at a depth into the back where additional confinement allows the plastic deformation to occur without failure of the back.

The instrumentation has confirmed that the stronger and less ductile halite of the A5 formation exhibits very little differential displacement at both locations. 


\section{Conclusion}

Magensonic extensometers used at the Vanscoy Mine demonstrated the benefits of a stiff ground support system in a medium in which the long-held view was to employ soft support systems to accommodate the time-dependant creep behaviour of potash. Removing the wood washer on resin anchored rebar support stiffened the ground support system with the result that the safe serviceable life of man entry excavations was extended and mineral resource that may have been lost due to deteriorating ground conditions can be safely extracted.

\section{References}

Baar, CA 1971, 'Applied rock mechanics in deep potash mines - creep and stress redistribution upon mining deep salt and potash beds', Saskatchewan Research Council Report E 71-2.

Mackintosh, AD 1975, 'Applied rock mechanics: the development of safe travelways at the Cominco Potash Mine', Proceedings of the Tenth Canadian Rock Mechanics Symposium, Queen's University, Kingston, pp. 69-95.

Mraz, DZF 1972, 'The theory of flow and its practical application for pillar designs in deep potash mines', Western Miner, April 1972 , pp. 22-26.

Mraz, DZF 1973, 'Behavior of rooms and pillars in deep potash mines', Canadian Institute of Mining, Metallurgy and Petroleum Transactions, vol. 76, pp. 138-143.

Neely, DD 2014, Failure mechanism of resin anchored rebar in potash, MSc Thesis, Dept of Civil and Geological Engineering, University of Saskatoon, Saskatoon.

Prugger, FF 1979, 'The operation of the Cominco Potash Mine with special consideration of some principles of applied rock mechanics for strata control', Proceedings of the Fifth International Symposium on Salt, Hamburg, West Germany, pp. 319-332.

Serata, S 1972, 'The Serata stress control method of stabilizing underground openings', Proceedings of Seventh Canadian Rock Mechanics Symposium, Department of Energy, Mines and Resources, Ottawa, pp. 99-118. 